ECCOMAS Proceedia
COMPDYN 2021

$8^{\text {th }}$ ECCOMAS Thematic Conference on Computational Methods in Structural Dynamics and Earthquake Engineering

M. Papadrakakis, M. Fragiadakis (eds.)

\title{
MODAL ANALYSIS OF THE HISTORICAL SS FILIPPO E GIACOMO MASONRY ARCH BRIDGE IN ASCOLI PICENO (ITALY)
}

\author{
F. Gara ${ }^{1}$, G. Leoni ${ }^{2}$, M. Morici ${ }^{2}$ \\ ${ }^{1}$ Università Politecnica delle Marche, Department of Construction, Civil Engineering and Architecture \\ 60131 Ancona, Italy \\ f.gara@univpm.it \\ ${ }^{2}$ University of Camerino, School of Architecture and Design \\ 63100 Ascoli Piceno, Italy \\ e-mail: \{graziano.leoni, michele.morici\}@unicam.it
}

\begin{abstract}
This paper presents the experimental test campaign to calibrate a finite element model intended to evaluate the seismic vulnerability of the SS Filippo e Giacomo historical masonry arch bridge in Ascoli Piceno (Italy).

The bridge was built in $14^{\text {th }}$ century and had undergone very complex vicissitudes related mainly to exceptional floods; it was partially rebuilt twice and other strengthening works were carried out over the time. The bridge, which is almost completely built with travertine blocks, has a total length of $146 \mathrm{~m}$ and follows a slightly curved path. Six arches, the main of which is semi-circular with span of $25 \mathrm{~m}$ and the others are lancet arches with span of about $8 \mathrm{~m}$, support the carriageway that is about $8 \mathrm{~m}$ wide. The piers and abutments are founded on the bedrock and consequently some piers are deeply embedded in the sandy gravel deposit.

A campaign of experimental tests was executed encompassing onsite measurements of stresses and modulus of elasticity as well as laboratory measurements on specimens taken from the structures. Vibration tests were also carried out to evaluate the modal properties of the bridge. The acquired experimental data were used to calibrate a 3D model that has been developed also including the soil deposit. A very good consistency was achieved between experimental and theoretical behaviors.
\end{abstract}

Keywords: Stone Masonry Bridges, Finite Element Models, Modal Analysis, Ambient Vibrations, Experimental In-Situ Tests.

ISSN:2623-3347 C 2021 The Authors. Published by Eccomas Proceedia.

Peer-review under responsibility of the organizing committee of COMPDYN 2021.

doi: 10.7712/120121.8742.18839 


\section{INTRODUCTION}

Evaluation of a historical masonry structure is a difficult task because of many uncertainties associated with the knowledge of the structure in its current conditions (original structure and structural changes due to repair enlargement and retrofit works, different construction systems and different materials, structural and material degradation and damages, soil and foundation modifications) and also due to modelling techniques complexity as well as to analysis methods. In this sense, after a deep historical analysis and a complete geometrical and structural survey, sophisticated measurement techniques are necessary to catch the real behaviour of the structure, especially the mechanical properties of the structural materials and the global dynamic behaviour.

About the material survey, both traditional techniques and innovative methods are available but non destructive techniques are generally preferred when dealing with historic and valuable structures. An extensive test campaign on material may permit to fix a large part of the most important parameters in the definition of the structural finite element model. The global dynamic behaviour of the structure can be experimentally determined by means of several kinds of test such as forced, impulse, release or ambient vibration tests, by using modal identification methods [1], [2], [3]. In the last decades ambient vibration test, with the relevant output-only modal identification methods, has become the preferred test typology for evaluating the modal parameters of full scale structures and especially for historic structures since no artificial excitation is required and the test can be carried out in operational conditions without interrupting the use of the structure and causing a minimum interference with it [4]. The experimental modal parameters can then be used to update refined finite element models able to describe the real behaviour of structures, which can be required for structural verifications and for designing repair and retrofit works [5], [6], [7].

This paper presents the experimental test campaign and the finite element model updating of the SS. Filippo and Giacomo Bridge over the Tronto river at Ascoli Piceno, in the centre of Italy. The bridge was built in the XIV century and was then subjected to many changes for repair, strengthening, retrofit, and enlargement works. This results in a large complexity of the structural organism, due to interaction between parts of different age which are made of materials with different mechanical proper-ties. Due to these uncertainties and considering the importance of the bridge an accurate analysis of its current conditions was deemed essential to obtain a reliable predictive finite element model to be used for the design of seismic retrofit. First of all a historic study and geometric survey of the bridge were developed. For the material properties in-situ tests, both destructive and non destructive, were carried out, to evaluate the quality of the travertine block masonry. These information were used to develop a refined 3D finite element model that was tuned based on the experimental modal parameters; in particular, the Young's modulus of some materials initially defined according to standard values suggested by codes, was calibrated to fit the dynamic behaviour obtained experimentally.

\section{2 “SS. FILIPPO AND GIACOMO" BRIDGE}

"SS. Filippo and Giacomo" Bridge rises in a less urbanized area of Ascoli Piceno town and crosses the Tronto River in a short straight section comprised between two loops. It was partially rebuilt twice and other strengthening works were carried out over the time.

It has a total length of $146 \mathrm{~m}$ and maximum height over $20 \mathrm{~m}$. The bridge is built between two rock escarpments; one of which is characterized by an important slope (Figure 1).

Six arches constitute the bridge. The main arch crosses the river during its regular flow and has a semicircular shape with span of about $25 \mathrm{~m}$. The arch barrel has the minimum thickness of $0.90 \mathrm{~m}$ at the crown and increases up to $1.40 \mathrm{~m}$ at the imposts. 


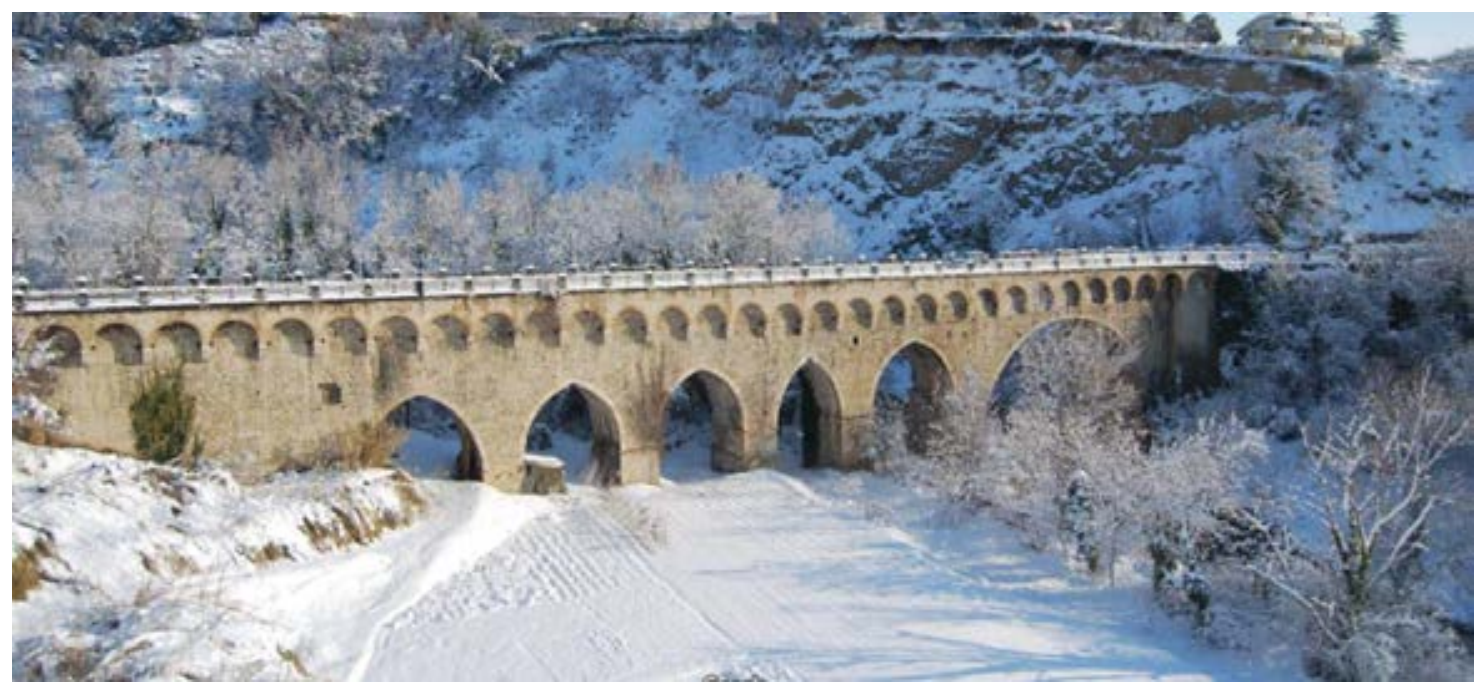

Figure 1: Aerial photogrammetric bridge view.

The other five arches are lancet shaped with span of about $8 \mathrm{~m}$. The depth of the fill at the crowns of arches is variable from about 6.0 to $7.5 \mathrm{~m}$. The spandrel walls have thickness of about $1.0 \mathrm{~m}$. All the piers are placed at the right bank occupied by the river during exceptional floods. The plan path is mostly rectilinear with a bend in proximity of the left abutment.

The two-lane road is almost $6 \mathrm{~m}$ wide and is flanked by two about $1 \mathrm{~m}$ wide sidewalks that were realized in the first half of the 20th century by enlarging the bridge with a double series of pensile semicircular small arches, with spans of about $4 \mathrm{~m}$, sustained by stone corbels.

The bridge, is completely built with travertine blocks with exception of the twentiethcentury pensile arches and of inner lightening rooms that are realized with brick masonry.

\subsection{Geometrical, material and geological survey}

The range-based survey used to acquire geometrical/metric data was made by means of a 3D-TOF laser scanner technique. Both the external geometry and the geometry of the various internal vaulted rooms over the main arch, at the pier top and at the abutments, were surveyed. Wooden and steel ties, placed to avoid the spandrel wall overturning toward outside were also surveyed in the accessible zones. The acquired dataset was then processed to obtain a refined 3D geometrical model that was later used to generate a structural model with very precise geometry and rigorous mass distributions. Such a kind of survey revealed to be extremely useful in the case under consideration characterized by a very complex geometry.

Piers is characterized by an external curtain, having variable thickness and realized with Ascoli Piceno travertine squared blocks, and an important internal, rather irregular, rubble stone infill characterized by the presence of water in the lower parts. For what concerns the masonry of the interior vaulted rooms, it was built with a good quality brick masonry. Nevertheless, it is worth noticing that such components are not expected to give a significant contribution to the overall behavior of the structure excepting for the mass.

The bridge rises between two rock escarpments produced by erosion of Tronto River (Figure 2). The left escarpment has a rather high slope $\left(52^{\circ}\right)$ whereas the right one is less sloping $\left(31^{\circ}\right)$. The gorge is characterized by a sandy gravel deposit on the right riverbank, with variable thickness up to $10 \mathrm{~m}$, whereas the sandstone bedrock is outcropping at the left riverbank. Investigations carried out in correspondence of piers P1, P2 and P3 demonstrated that foundations are placed at the sandstone bedrock which is horizontal; despite other specific analyses were not carried out for the other piers (P4 and P5) there is no evidence (e.g. vertical settlements) that these are founded over the deposit; the sandy gravel deposit is thus placed around the pier but not under the foundation layer. 

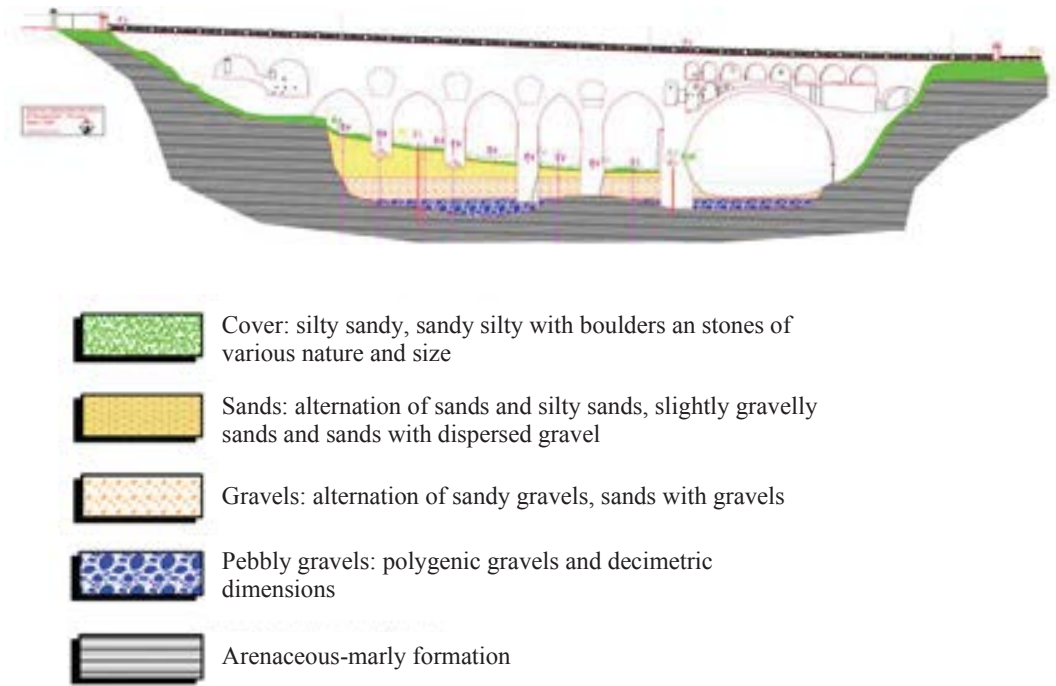

Figure 2: Geological configuration and foundation level.

\section{OPERATIONAL MODAL TESTING}

\subsection{Instrumentation and tests}

The modal parameters of the bridge, i.e. natural frequencies, damping ratios and mode shapes, are experimentally estimated by means of operational modal analysis starting from the accelerations of the deck recorded during ambient vibration measurements which are mainly due to traffic, wind and microtremors. The tests are performed by using 8 low noise piezoelectric uniaxial accelerometers, a 24-bit data acquisition system, and coaxial cables (Figure 3). Different configurations are adopted in order to identify the global behaviour of the bridge; in this paper only that useful to investigate the transversal behaviour is reported and analysed.

Two configurations was considered in order to capture transversal and vertical-torsional behavior of the bridge (Figure 4). In order to capture the transversal behavior, 8 accelerometers aligned throughout the longitudinal axis of the bridge and oriented in transverse direction were installed (Configuration 1), while to capture the flexural-torsional response, 8 accelerometers lined up in pairs and oriented in vertical direction were installed (Configuration 2).

Time histories 1000 seconds long, sampled at a rate of $2048 \mathrm{~Hz}$ (the minimum sampling rate for the used data acquisition system), were acquired. This time length provides enough data to obtain modal parameters with a good accuracy, as reported in [8] where an acquisition time longer than about 1000-2000 times the fundamental period, is recommended (in this case a value of about $2.5 \mathrm{~Hz}$ was obtained from preliminary measurements that leads to $400-800 \mathrm{~s}$ ).

Before performing the operational modal analysis all the recorded data were processed by means of suitable signal processing techniques: trend removal, low-pass filtering (to eliminate the contribution of high frequencies and to avoid aliasing phenomena) and down-sampling at $51.2 \mathrm{~Hz}$, in order to decrease the amount of data and make faster the successive analyses. 


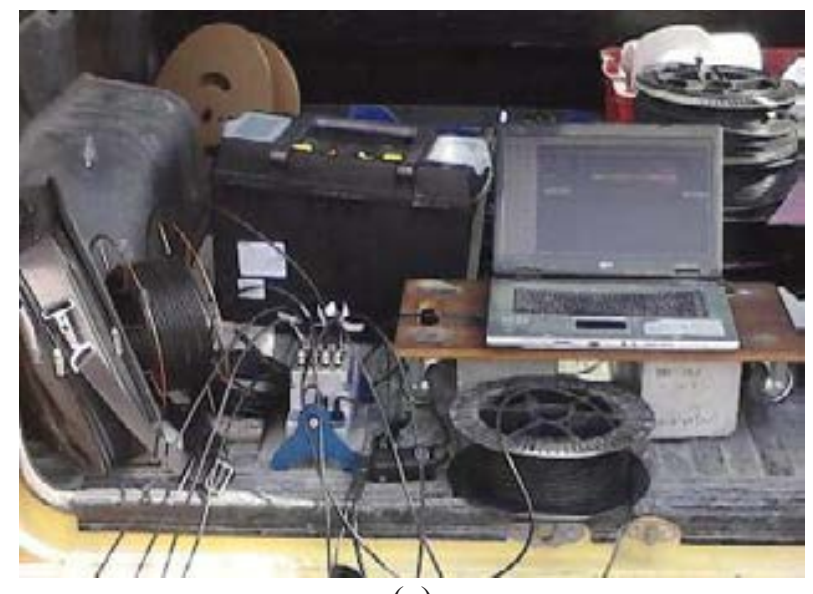

(a)

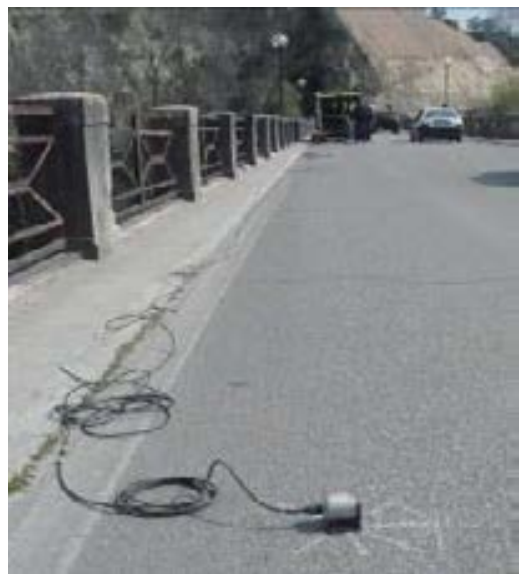

(b)

Figure 3. Instrumentation and uniaxial accelerometers.

\section{Configuration 1}

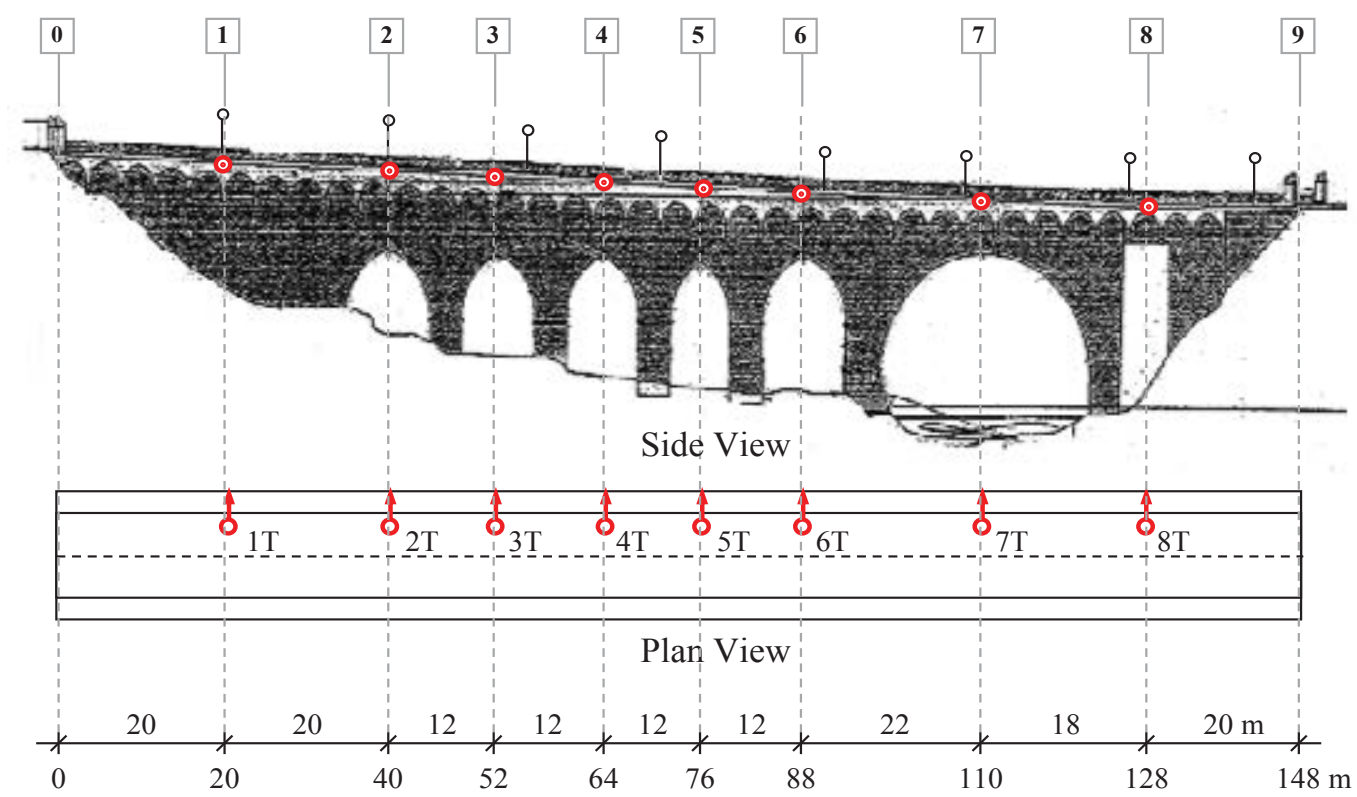

Configuration 2

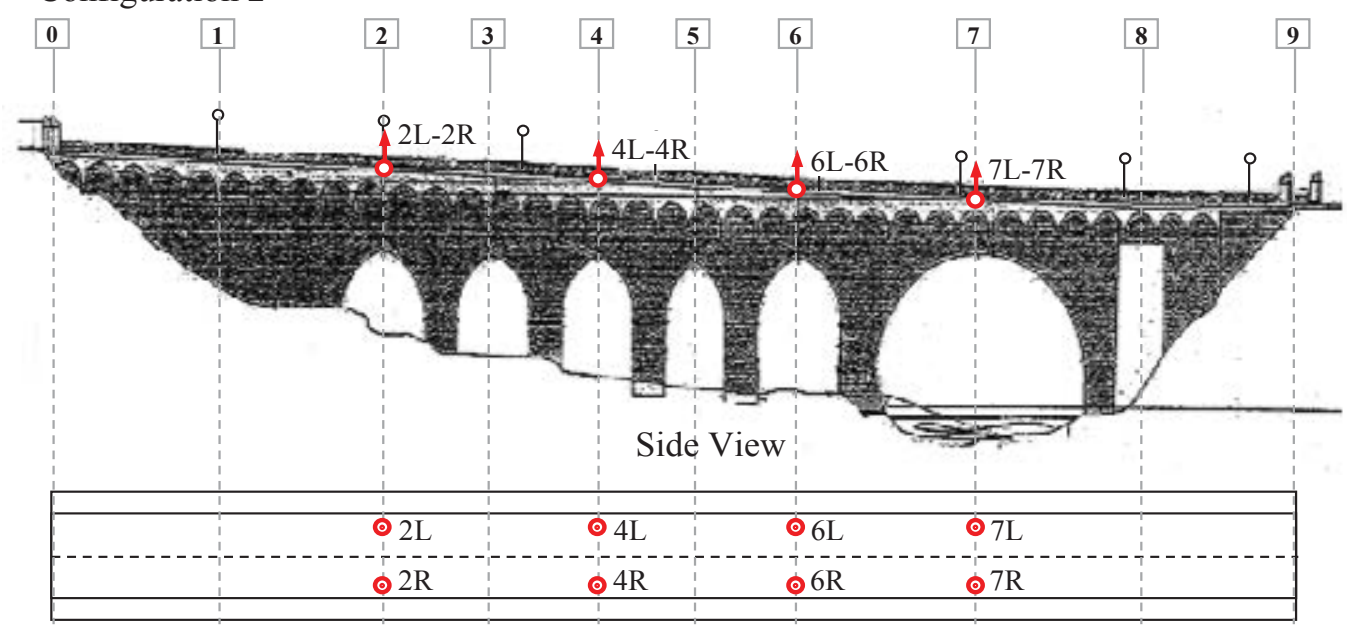

Plan View

Figure 4. Location of accelerometers for the two configurations 


\subsection{Operational modal analysis (methods and results)}

The Covariance-Driven Stochastic Subspace Identification (SSI-Cov) is used to estimate the modal parameters on the basis of the accelerations recorded during the ambient vibration test. This method uses a stochastic state-space model, simplifying the second-order system of differential equation that describes the dynamic problem into a first-order system. Starting from the recorded data sampled at discrete interval, the stochastic state-space model is represented by [9]

$$
\begin{gathered}
\mathbf{x}_{k+1}=\mathbf{A} \mathbf{x}_{k}+\mathbf{w}_{k} \\
\mathbf{y}_{k}=\mathbf{C} \mathbf{x}_{k}+\mathbf{v}_{k}
\end{gathered}
$$

where $\mathbf{x}_{k}$ is the discrete-time state vector at time instant $k, \mathbf{y}_{k}$ is the vector of the output, $\mathbf{A}$ is the discrete state matrix, $\mathbf{C}$ is the discrete output matrix, and $\mathbf{w}_{k}$ and $\mathbf{v}_{k}$ represent the process and measurement noise respectively. The Toeplitz matrix containing the covariance matrices of measured accelerations is used to extract $\mathbf{A}$ and $\mathbf{C}$ matrices by means of a Singular Value Decomposition and a least square procedure [10]. The modal parameters are obtained by the two matrices characterizing the state-space model. The SSI-Cov permits the estimation of a number of modes depending on the model order used in the state-space model. The physical modes are separated by the spurious ones by means of the stabilization diagram which allows the identification of (y-axis) the stable modes (x-axis) i.e. the modes presenting modal parameters (natural frequencies, damping ratios and mode shapes) which remain similar as the model order increases (Figure 5). In this work models with up to 40 order are used and the modes are considered to be consistent if, when increasing the model order one by one: (i) natural frequency variation is less then $1 \%$, (ii) damping ratio variation is less than $2 \%$, and (iii) Modal Assurance Criterion (MAC) between the modes is greater than $98 \%$.

Table 2 reports the natural frequencies with the relevant damping ratios obtained with the operational modal analysis in the frequency range 2-6 Hz from Configuration 1, while Figure 6 shows the normalized modal shapes obtained with SSI-Cov method. The modes identified are the transversal modes typical for such a masonry bridge. The modal parameters estimated experimentally are crucial to evaluate the reliability of the model and to calibrate some important parameters. Table 3 reports the natural frequencies with the relevant damping ratios obtained with the operational modal analysis from Configuration 2, while Figure 7 shows the normalized modal shapes obtained with SSI-Cov method.

In this case the natural frequencies and mode shapes estimated in Configuration 1 are used in the sequel to calibrate the mass distribution along the bridge length (based on some assumption in absence of experimental survey) and the elastic modulus of the travertine masonry.

\begin{tabular}{llll}
\hline Mode & $f(\mathrm{~Hz})$ & $\xi(\%)$ & Mode shape \\
\hline 1 & 2.46 & 2.11 & $1^{\text {st }}$ transverse \\
2 & 3.30 & 2.97 & $2^{\text {nd }}$ transverse \\
3 & 4.54 & 2.54 & $3^{\text {rd }}$ transverse \\
4 & 5.61 & 2.50 & $4^{\text {th }}$ transverse \\
\hline
\end{tabular}

Table 2: Modal parameters from Configuration 1. 


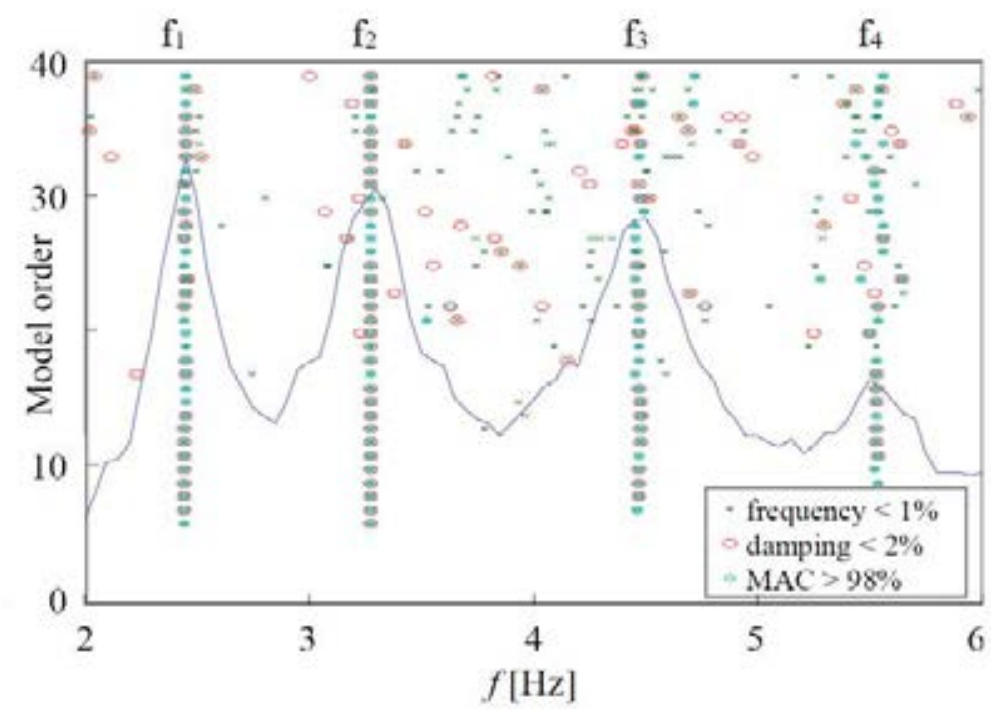

Figure 5. Stabilization diagram

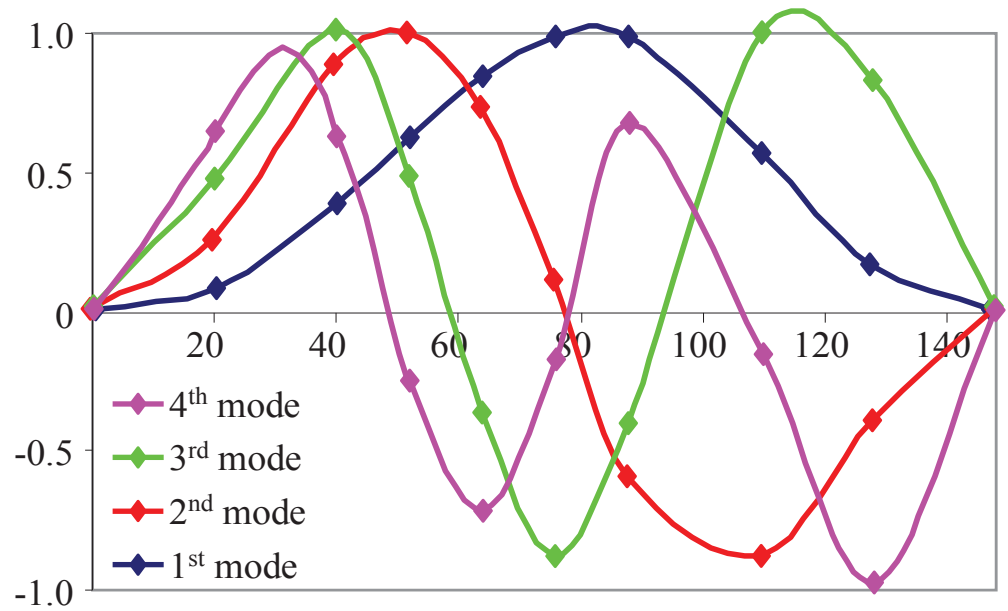

Figure 6. Experimental transverse mode shapes.

\begin{tabular}{llll}
\hline Mode & $f(\mathrm{~Hz})$ & $\xi(\%)$ & Mode shape \\
\hline $1^{\circ}$ & 6.27 & 3.88 & Flexural mode \\
$2^{\circ}$ & 8.55 & 1.67 & Flexural mode \\
$3^{\circ}$ & 9.68 & 5.27 & Flexural mode \\
$4^{\circ}$ & 12.40 & 3.54 & Flexural mode \\
$5^{\circ}$ & 14.07 & 2.02 & Torsional mode \\
\hline
\end{tabular}

Table 3: Modal parameters from Configuration 2. 
$1^{\text {st }} \operatorname{MODE}\left(f_{1}=6.27 \mathrm{~Hz}\right)$

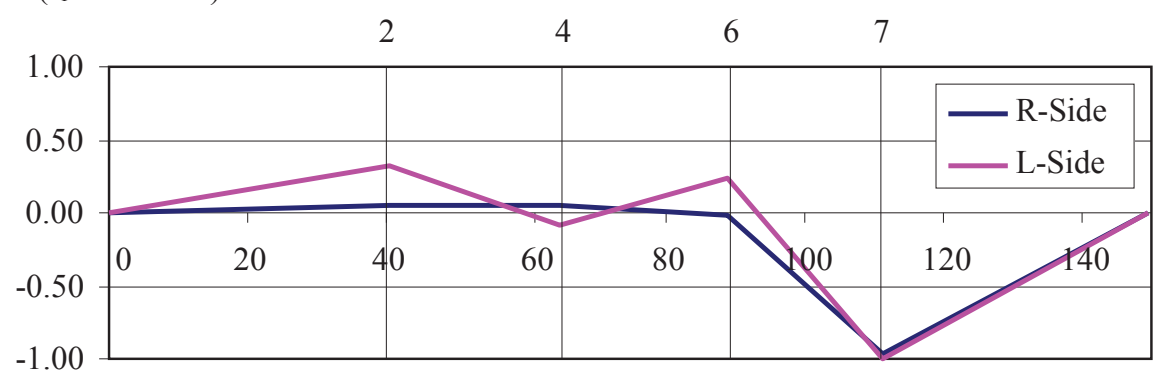

$2^{\text {nd }} \operatorname{MODE}\left(f_{2}=8.55 \mathrm{~Hz}\right)$

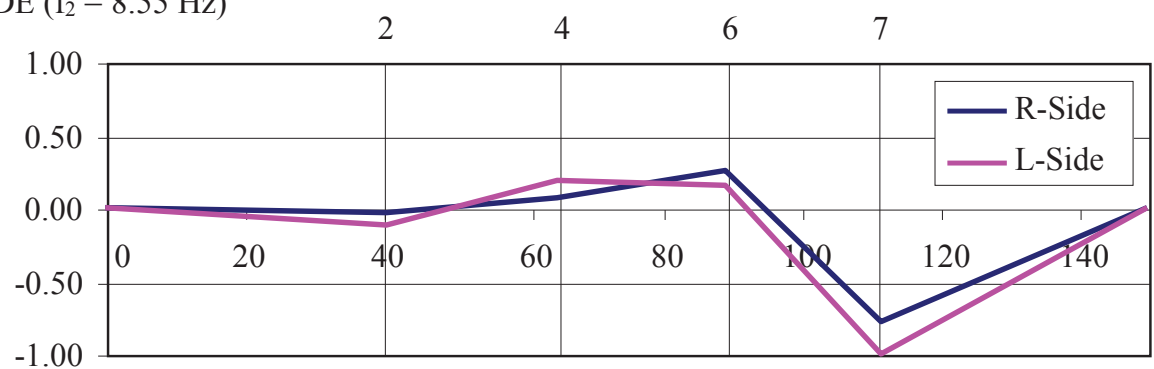

$3^{\text {rd }} \operatorname{MODE}\left(f_{3}=9.68 \mathrm{~Hz}\right)$

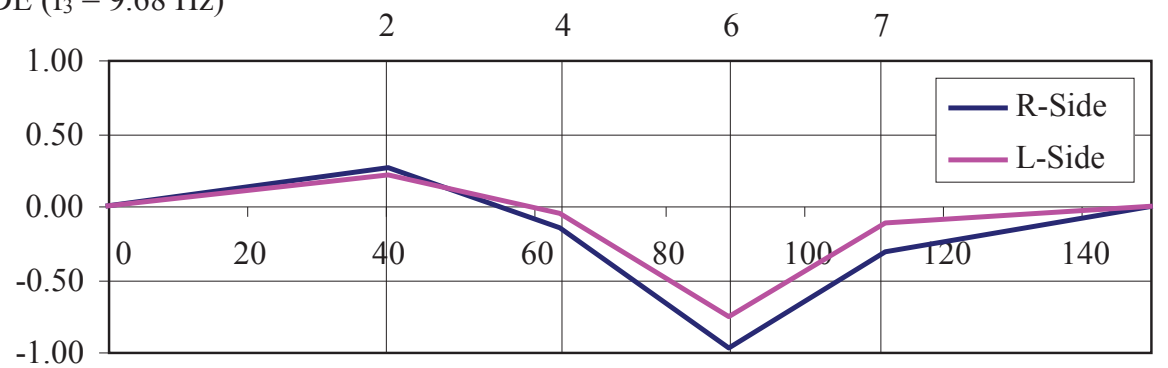

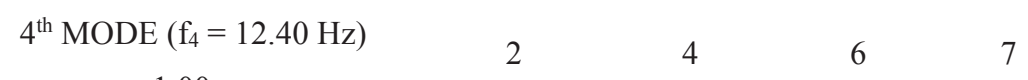

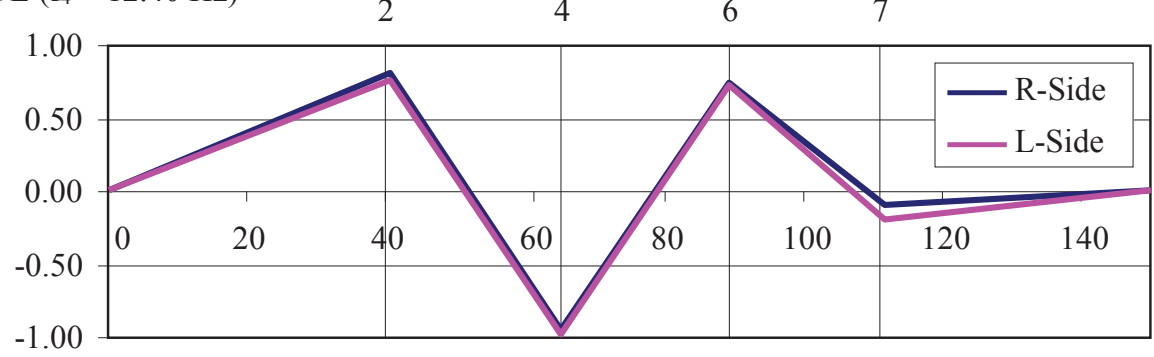

$5^{\mathrm{h}} \operatorname{MODE}\left(\mathrm{f}_{5}=14.07 \mathrm{~Hz}\right)$

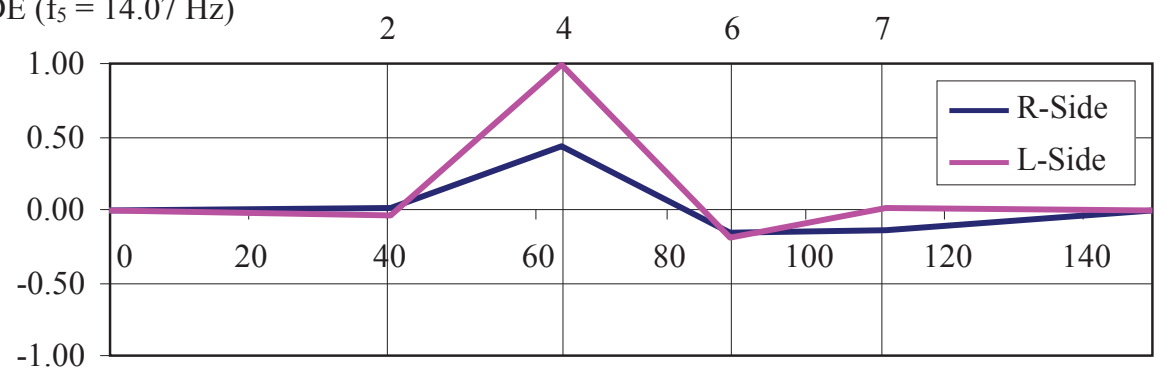

Figure 7. Experimental vertical mode shapes. 


\section{STRUCTURAL MODEL OF THE BRIDGE}

\subsection{Finite element model}

Model for the overall structural analysis is developed in Straus7 [11] by integrating data available from the laser scanner survey. In particular, the 3D model (Figure 8a) encompasses a suitable portion of the soil deposit with variable depth in order to account for the particular geological configuration and to capture effects of soil-pier interaction.

The finite element model is obtained with a mesh of 4-node tetrahedral elements with linear interpolation shape functions (Tetra4). The mesh is generated by importing a closed polysurface constructed by approximating the geometry obtained with the laser scanner survey.

For such a purpose the geometry is simplified in order to avoid excessive refinement of the mesh due to details that do not actually affect the overall behavior of the bridge; at the same time all internal rooms and the earth fill are modelled in order to capture the real stiffness and mass distribution of the structure. Maximum length imposed to the element edge is $1.0 \mathrm{~m}$ for the bridge structure whereas it is increased up to $4.5 \mathrm{~m}$ for the elements of the soil deposit (Figure 8b). Fixity restraint are placed at the deposit base and at the structure sections interacting with the sand stone formation. The model is constituted by 120,545 elements for a total of 75,204 degrees of freedom. All the materials, including earth fills and the soil deposit, are considered to be linear elastic and isotropic.

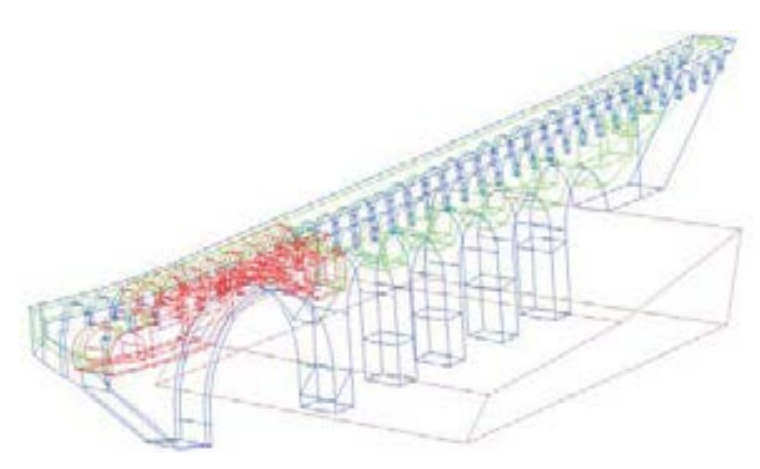

(a)

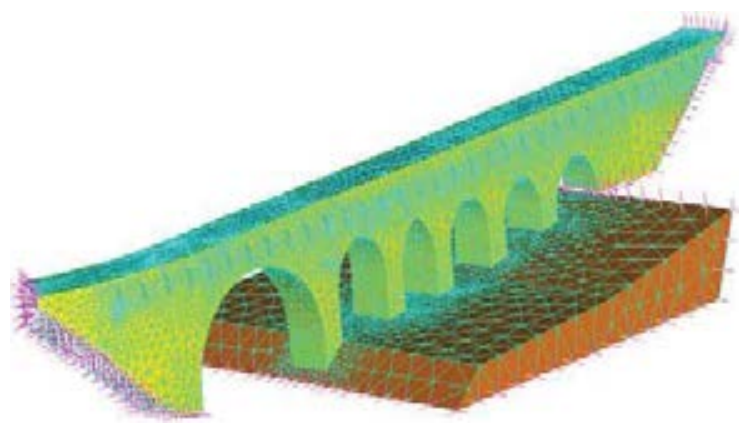

(b)

Figure 8. (a) Geometrical model; (b) Finite element model.

\subsection{Model tuning}

The mechanical parameters of the finite element model are calibrated by fitting the experimental modal parameters with numerical ones relevant to the finite element model previously discussed. Initial value of the parameters are selected according to the valued reported in the Italian standard [12-13].

Figure 9a shows the first four mode shapes obtained by means of model calibration changing only the elastic modulus of the travertine masonry constituting the main structure. In Figure $9 \mathrm{~b}$ the comparison among the first four experimental and numerical mode shapes is reported, while Table 4 reports the percentage errors relevant to the frequencies and the approximation of the mode shapes by means of the MAC

$$
M A C=100 \times \frac{\left(\boldsymbol{\varphi}_{i} \cdot \widetilde{\boldsymbol{\varphi}}_{i}\right)^{2}}{\left(\boldsymbol{\varphi}_{i} \cdot \boldsymbol{\varphi}_{i}\right)\left(\widetilde{\boldsymbol{\varphi}}_{i} \cdot \widetilde{\boldsymbol{\varphi}}_{i}\right)}
$$

which tends to 100 when the theoretical $\left(\boldsymbol{\varphi}_{i}\right)$ and experimental $\left(\widetilde{\varphi}_{i}\right)$ modes tends to be equal. 

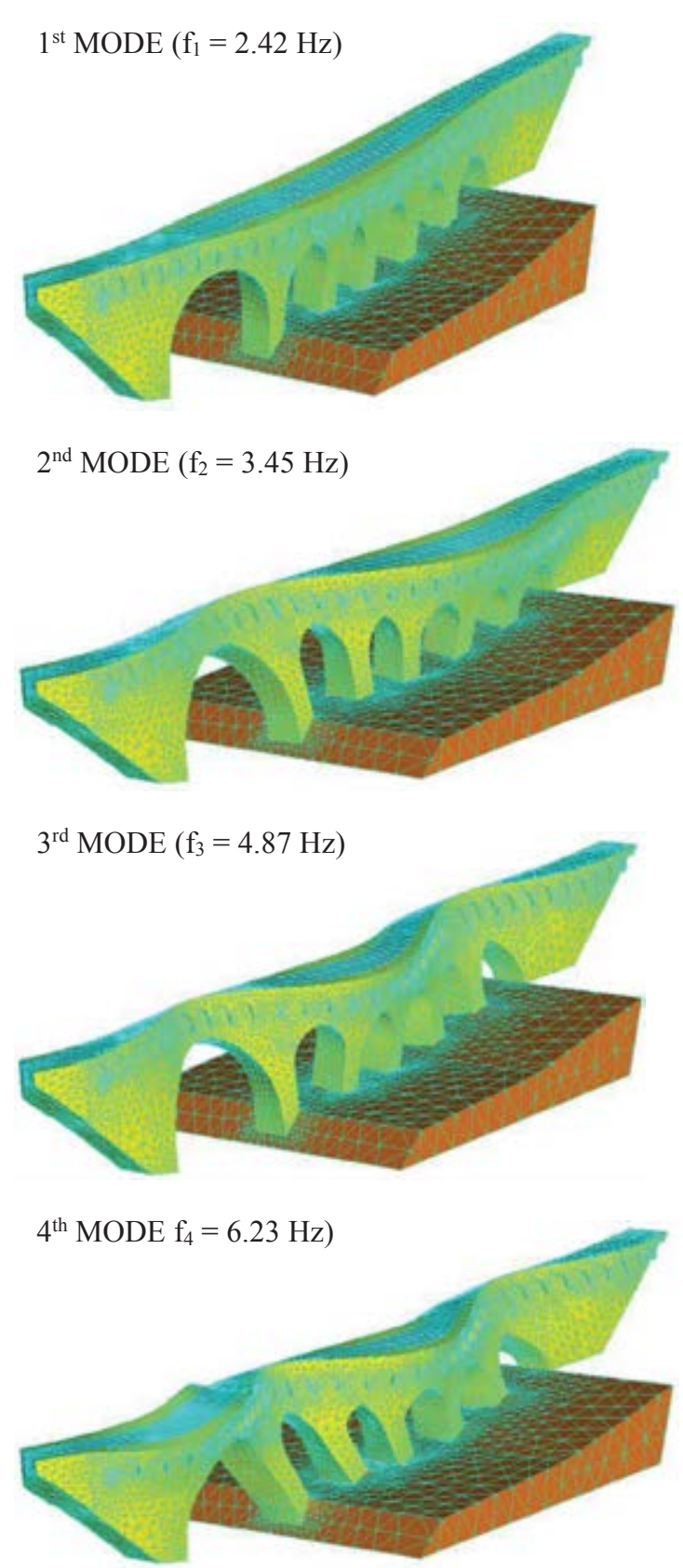

(a)
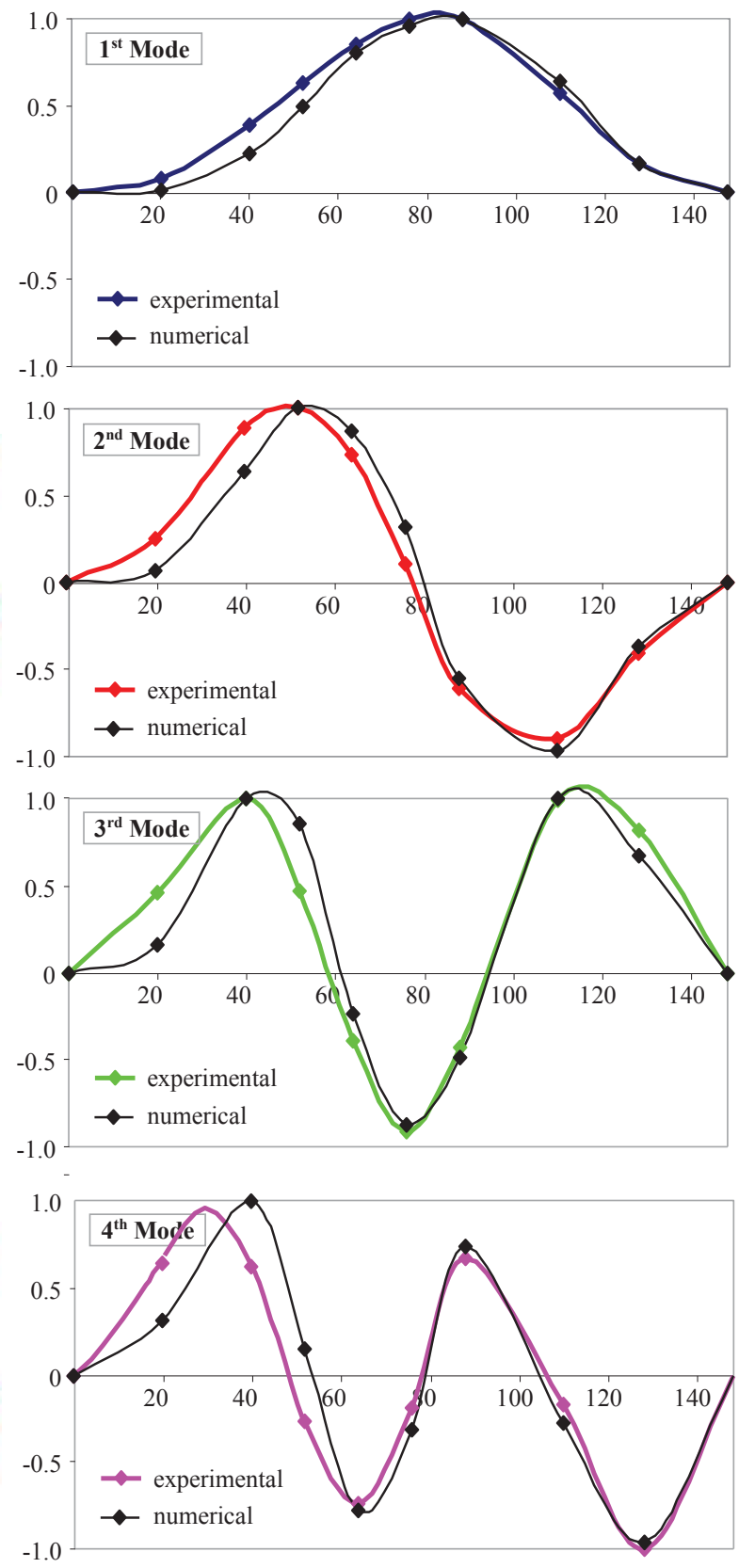

(b)

Figure 9. (a) First four transverse vibration modes; (b) Comparison between experimental and numerical modes

\begin{tabular}{|c|c|c|c|c|}
\hline \multirow{2}{*}{ Mode } & \multicolumn{2}{|c|}{ Frequency $(\mathrm{Hz})$} & \multirow{2}{*}{$\begin{array}{l}\text { Error } \\
(\%)\end{array}$} & \multirow{2}{*}{$\begin{array}{l}\text { MAC } \\
(\%)\end{array}$} \\
\hline & Experimental & Numerical & & \\
\hline 1 & 2.46 & 2.42 & 1.55 & 98.58 \\
\hline 2 & 3.30 & 3.45 & -4.67 & 95.43 \\
\hline 3 & 4.54 & 4.87 & -7.34 & 93.37 \\
\hline 4 & 5.61 & 6.23 & -10.99 & 86.45 \\
\hline
\end{tabular}

Table 4. Comparison between experimental and numerical results 
The parameters used in the model are reported in Table 5. The soil parameters are derived from geotechnical tests while infill materials are hypothesized.

\begin{tabular}{llll}
\hline Material & $\begin{array}{l}\mathrm{E} \\
\left(\mathrm{N} / \mathrm{mm}^{2}\right)\end{array}$ & $\begin{array}{l}\mathrm{G} \\
\left(\mathrm{N} / \mathrm{mm}^{2}\right)\end{array}$ & $\begin{array}{l}\mathrm{W} \\
\left(\mathrm{kN} / \mathrm{m}^{3}\right)\end{array}$ \\
\hline Travertine masonry & 7000 & 2414 & 22 \\
\hline Brick masonry & 1282 & 427 & 18 \\
\hline Earth fill & 666 & 238 & 18 \\
\hline Soil deposit & 666 & 243 & 19 \\
\hline
\end{tabular}

Table 5. Mechanical parameters of materials

\section{CONCLUSIONS}

An experimental test campaign aimed at calibrating the finite element model of a historical masonry bridge, characterized by an unusual geometry deriving by very complex historical vicissitudes, has been presented. The bridge rises in a gorge and is founded on a sand-stone deposit that is outcropping at the abutments. The bridge is constituted by six different arches whose piers are founded on the sand-stone formation and are embedded for significant sections (up to $10 \mathrm{~m}$ ) into the fluvial deposit constituted by sandy-gravel soil.

A laser scanner survey was crucial to obtain a model encompassing all main features of the real structure such as the inner lightening rooms, with very irregular geometry, as well as the pensile arches constructed to enlarge the carriageway.

The onsite tests permitted the evaluation of the main mechanical characteristics of the materials and the estimation of the stress state in critical sections of the piers.

The operational modal analysis, used to detect the dynamic behavior of the bridge, was decisive for tuning a finite element model capable of predicting the overall behavior of the bridge.

\section{REFERENCES}

[1] F.Aras, L. Krstevska, L. Tashkov. Experimental and numerical modal analyses of a historical masonry palace. Constr Build Mater, 25(1): 81-91, 2011.

[2] G.C. Beolchini, F. Vestroni. Experimental and analytical study of dynamic behaviour of a bridge. J Struct Eng ASCE, 123(11): 1506-1511, 1997.

[3] D. Benedetti, C. Gentile. Identification of modal quantities from two earthquake responses. Earthquake Eng Struct Dynam, 23(4): 447-462, 1994.

[4] G. Gentile, A. Saisi. Ambient vibration testing of historic masonry towers for structural identification and damage assessment. Constr Build Mater, 21(6): 1311-1321, 2007.

[5] A. De Sortis, E. Antonacci, F. Vestroni. Dynamic identification of a masonry building using forced vibration tests. Eng Struct, 27(2): 155-165, 2005.

[6] H. Ahmadian, G.M. Gladwell, F. Ismail. Finite element model identification using modal data. J Sound Vib, 172(5): 657-669, 1994.

[7] J.E. Mottershead, M.I. Friswell. Model updating in structural dynamics: a survey. $J$ Sound Vib, 167(2): 347-375, 1993. 
[8] Cantieni, R. Experimental methods used in system identification of civil engineering structures. Proc. $1^{\text {st }}$ Int. Operational Modal Analysis Conf., Copenhagen, Denmark, pp. 249-260, 2005.

[9] J.-N. Juang. Applied System Identification. Prentice-Hall Englewood Cliffs, New Jersey, USA, 1994.

[10] P. Van Overschee, B. De Moor. Subspace identification for linear systems: theoryimplementation-applications. Dordrecht, The Netherlands: Kluwer Academic Publishers, 1996.

[11] Straus7, G+D Computing Pty Limited, http://www.straus7.com

[12] Norme tecniche per le costruzioni. D.M. Ministero Infrastrutture e Trasporti 2018, Supplemento ordinario alla "Gazzetta Ufficiale n. 42 del 20 febbraio 2018 - Serie generale (In italian), 2018

[13] Istruzioni per l'applicazione delle Nuove norme tecniche per le costruzioni di cui al decreto ministeriale 14 gennaio 2018. Ministero delle Infrastrutture e dei Trasporti e Consiglio Superiore dei Lavori Pubblici, Circolare 21 gennaio 2019, n. 7. Gazzetta Ufficiale n. 35 del 11 febbraio 2019 - supplemento ordinario n. 5 (in Italian), 2019. 